\title{
AS BIBLIOTECAS DAS ESCOLAS E CURSOS DE AUXILIAR DE ENFERMAGEM DO ESTADO DE SÃO PAULO *
}

\author{
Atsuko Yamamoto** \\ Lourdes Kimie Hirata**
}

YAMAMOTO, A. \& HIRATA, L. K. As bibliotecas das Escolas e Cursos de Auxiliar de Enfermagem do Estado de São Paulo. Rev. Esc. Enf. USP, São Paulo, 14(1): $89-99,1980$.

Apresentam-se os resultados de um levantamento realizado em bibliotecas de trinta $e$ nove Escolas e Cursos de Auxiliar de Enfermagem do Estado de São Paulo em 1978, nos aspectos de acervo, área física e funcionamento.

\section{INTRODUÇÃO}

O termo biblioteca, etimologicamente, significa "depósito de livros" (do grego bibliothéke, pelo latim bibliotheca) ${ }^{4}$.

Os dicionários definem este termo como uma "coleção de livros classificados em determinada ordem: acervos, arquivos documentais - condensam a tradição escrita humana" 5.

Entendemos por biblioteca um local de estudo e consulta onde estão dispostos livros e periódicos de maneira organizada e com acomodação para quem os utiliza.

Segundo SCHRAMN 14 "uma biblioteca bem organizada é de grande valor no planejamento do programa da escola e propicia condições para sua execução".

A mesma autora comenta que, "durante o planejamento de um curso, o professor deverá estabelecer os recursos a serem utilizados no desenvolivmento, principalmente as referências bibliográficas, de acordo com as disponibilidades da biblioteca da sua escola".

MARQUES ${ }^{8}$ referindo-se também a esse aspecto lembra que "o professor não é a única fonte de informação para o aluno e que o uso de bibliografia é um dos recursos indispensáveis para efetivar um bom ensino".

BORDENAVE PEREIRA ${ }^{1}$, em seu livro ESTRATÉGIAS DE ENSINOAPRENDIZAGEM, questiona: "Por que os alunos lêem pouco? Cita como pontos chaves desse problema: "o professor e os alunos devem conhecer a biblioteca da escola à qual pertencem, principalmente a organização do material bibliográfico; o estudante deve desenvolver hábitos de leitura e pesquisa bibliográfica que lhe permitam adquirir e renovar seus conhecimentos na biblioteca, dentro do processo global de aprendizagem".

\footnotetext{
- Trabalho apresentado à disciplina Prática de Ensino de Enfermagem do Curso de Licenciatura de Enfermagem da Faculdade de Educaçāo da USP em 1978. Orientação da docente Victória Secaf, da Escola de Enfermagem da USP.

* Enfermeira diplomada pela Escola de Enfermagem da USP em 1979
} 
É reconhecida por todos a importância da existência de biblioteca num estabelecimento de ensino.

Trazendo as exposiçōes teóricas apenas o essencial do assunto da aula, é de grande valor haver recursos para complementá-lo.

As referências bibliográficas são um dos meios auxiliares mais utilizados e de fácil acesso.

No ensino de Enfermagem, nos seus diferentes niveis, é dada ênfase à parte prática, porém não se dispensa o uso de biblioteca ${ }^{12}$.

O Guia para Escuelas de Enfermería en la America Latina, elaborado em 1961, estabelece que, para a organização de Escolas de Enfermagem, são necessárias várias comissões e entre elas a de Biblioteca. A referida comissão teria como uma das funções: estabelecer e interpretar os procedimentos para o uso e manejo da biblioteca; estimular seu uso e incrementar seu conteúdo, selecionar e manter em dia seu material.

CARVALHO ${ }^{3}$ apresenta sugestões para o acervo mínimo de biblioteca de Escola de Enfermagem ao nível de graduação.

CALDAS ${ }^{2}$ enumera os requisitos mínimos e indispensáveis para a organização de uma biblioteca de Escola de Auxiliar de Enfermagem, relacionados aos: objetivos, clientela, meios, rotina e catalogação.

A mesma autora e SCHRAMN ${ }^{14}$ reforçam a importância da Escola contar com um bibliotecário, que mantenha contato constante com o corpo docente, com conhecimento da organização e do acervo existente para orientar os alunos. Na falta desse profissional um funcionário deverá ser treinado para esta atividade. Os alunos deverão ser orientados quanto a: organização da biblioteca, prática de procura e consulta a livros e periódicos.

Como alunas do curso de graduação em Enfermagem, aprendemos a conhecer e valorizar a existência da biblioteca da Escola.

No curso de iLcneciatuara, pelos conhecimentos teóricos adquiridos e por visitas efetuadas às Escolas de Técnicos e de Auxiliares de Enfermagem constatamos a importância que os livros e periódicos têm para os alunos e docentes.

Será que todas as Escolas e Cursos de Auxiliar de Enfermagem do Estado de São Paulo possuem uma biblioteca?

Como seriam suas suas instalações e organização?

Obter respostas a estas perguntas contsitui o nosso motivo para este trabalho.

\section{OBJETIVO}

Fazer levantamento das bibliotecas das Escolas e Cursos de Auxiliar de Enfermagem do Estado de São Paulo.

\section{HIPÓTESES}

1 - Todas as Escolas e Cursos de Auxiliar de Enfermagem do Estado de São Paulo possuem livros e periódicos para o uso do docente e discente. 
2 - Na grande maioria das Escolas e Cursos estes livros estão localizados em estante fora de uma área física específica (Biblioteca).

3 - As bibliotecas das Escolas e Cursos funcionam sem organização adequada ,o que dificulta o atendimento dos consulentes.

\section{DEFINIÇÃO DE TERMOS}

Alguns termos utilizados em Biblioteconomia que constarão desse trabalho:

ACERVO - Conjunto de material bibliográfico: livros, periódicos, material audio-visual, pranchas, álbum seriado, folheto, teses, separatas, etc., que constituem a coleção de uma biblioteca.

CATÁLOGO - Armários de aço contendo gavetas nas quais são arquivadas as fichas de acordo com a catalogação adotada.

FICHÁRIO - Refe-se às publicações que são editadas dentro de um periodo pré-estabelecido. São os jornais e revistas.

PERMUTA - Refere-se aos periódicos que chegam em duplicata na instituição; são anotados na lista e posteriormente oferecidos a outras entidades como material de permuta.

PESQUISA BIBLIOGRÁFICA - Processo de procura de informação em documentos para determinar qual ć o conhecimento existente em uma área particular.

\section{CARACTERIZAÇÃO DO UNIVERSO}

No Estado de São Paulo, existem vinte e nove Escolas e Cursos de Auxiliar de Enfermagem, segundo o Relatório da Comissão de Documentação e Estudos da Associação Brasileira de Enfermagem, de 1975-1976 ${ }^{9}$. Os nomes e endereços das Escolas e Cursos de Auxiliar de Enfermagem recém-criadas, até o ano de 1978, constam de uma relação fornecida pelo Conselho Regional de Enfermagem de São Paulo (COREN - SP).

As bibliotecas das Escolas e Cursos de Auxiliar de Enfermagem, motivo deste trabalho, que é limitado às do Estado de São Paulo, são em número de trinta te nove, o que correspondem a $43,3 \%$ do total das Escolas e Cursos de Auxiliar de Enfermagem do Brasil.

Do total do universo, trinta e nove escolas, constatou-se que vinte e seis situam-se no interior do Estado de São Paulo e as restantes, treze, estão na Capital.

Pode-se observar também que vinte e três escolas funcionam isoladas, dez fazem parte de uma instituição maior que mantém cursos técnicos e profissionalizantes, e seis funcionam junto a uma Escola de Enfermagem.

\section{METODOLOGIA}

\section{I - Instrumentos utilizados}

Para este levantamento utilizamos:

- carta de apresentação, esclarecendo o objetivo do trabalho e pedindo a colaboração da Direção da escola ou Curso (Anexo I); 
- envelope selado e endereçado ,já subscrito em nome das Autoras, para facilitar a devolução dos questionários respondidos;

\section{- questionário com doze perguntas fechadas (Anexo II).}

Devido à maioria das Escolas e Cursos de Auxiliar de Enfermagem localizar-se no interior do Estado, e pela possibilidade de ser mais fácil e ser respondido, escolhemos o questionário como instrumento deste estudo.

NOGUEIRA 11 diz que o "questionário é uma série de perguntas organizadas com o objetivo de levantar dados para uma pesquisa, cujas respostas são fornecidas pelo informante ou pesquisado sem a assistência direta ou orientação do investigador. É geralmente enviado ao informante ou pesquisado, pelo correio, ou por portador, sendo do mesmo modo desenvolvido ao investigador".

O primeiro instrumento elaborado foi revisto e refeito após um teste piloto aplicado à Diretora de uma das Escolas. Para que o questionário se adequasse à realidade que encontraríamos foi obtida a colaboração de um docente e das bibliotecárias da Escola de Enfermagem da Universidade de São Paulo.

As questões de número 1 e 2 referem-se à área física e instalações da biblioteca, que são aspectos importantes para que o consulente tenha um ambiente adequado para leitura e estudo e saiba encontrar o que procura.

As questões de número 3 a 8 referem-se ao funcionamento da biblioteca que, se adequado, estimula o acesso a ela. $O$ bom funcionamento é um incentivo para que os alunos a utilizem. As normas escritas de funcionamento propiciam melhor atendimento aos consulentes. $\mathrm{O}$ uso adequado do fichário facilita localizar mais rapidamente o livro desejado.

A fim de obtermos dados sobre o acervo bibliográfico que um aluno de Curso de Auxiliar de Enfermagem necessita para a sua formação vocacional utilizamos as questóes de número 10 e 11 .

O periódicos são importantes, e segundo BORDENAVE ${ }^{1}$ o professor deveria manter-se atualizado na literatura profissional e preparar os alunos para enfrentar o constante fluxo de novos conhecimentos (questão número 12).

O mesmo autor afirma também que o "professor deve conseguir que a biblioteca tenha exemplares suficientes das obras de consulta mais freqüentes para a sua disciplina, o que ocorrerá se ele (professor) opinar na aquisição de livros" (questão número 9).

\section{2 - Coleta de dados}

Dos trinta e nove questionários, foram enviados vinte e quatro pelo correio para o interior do Estado, no periodo de 10 a 12 de maior de 1978. A correspondência incluía também a carta de apresentação, o envelope selado e endereçado à Escola de Enfermagem da Universidade de São Paulo. A carta foi assinada pelas Autoras e pela docente de prática de Ensino de Enfermagem. Pedíamos que nos fosse devolvido o questionário respondido até o dia 29 de maio.

A entrega dos questionários para as Escolas e Cursos da cidade de São Paulo, (em nmero de treze) foram feitas no periodo de 10 a 12 de maio, pessoalmente 
pelas autoras, para maior certeza de obtenção de respostas. Um dos quetsionários foi enviado juntamente com a carta, por um docente da escola a que se destinava, pela facilidade de contato com a Diretora.

Nas Escolas e Cursos em que fomos pessoalmente, apresentávamo-nos como alunas do Curso de Licenciatura em Enfermagem da Universidade de São Paulo, realizando um levantamento sobre bibliotecas nas Escolas e Cursos de Auxiliar de Enfermagem e solicitávamos entrevista com a Diretora. Não sendo possível, falávamos com quem nos fosse indicado, com o bibliotecário, ou o auxiliar de biblioteca, que nos prestava as informações necessárias.

Na entrevista, mostrávamos a carta e o questionário, e o entrevistado ou nós mesmas o preenchíamos. Na impossibilidade de sermos atendidas no momento, deixávamos o questionário e em data posterior ele era recolhido. Esta medida possibilitou a obtenção de doze respostas $(92,3 \%)$.

Dos vinte e quatro questionários enviados pelo correio para as Escolas e Cursos do interior, recebemos vinte e uma respostas $(80,7 \%)$.

No total, obtivemos trinta e três respostas $(84,6 \%)$, apesar de a maioria delas ter chegado às nossas mãos após o prazo sugerido na carta.

Uma das escolas explicava não ser possível colaborar pois foi desativada em 1973; outra devolveu o questionário sem responder, alegando não ter biblioteca. Uma terceira resposta não foi considerada pois chegou após a tabulação dos dados.

\section{RESULTADOS}

Recebemos trinta e três $(84,6 \%)$ respostas mas, para efeito do cálculo de porcentagem, consideraremos as trinta escolas que nos enviaram os questionários respondidos $, 76,9 \%$ dos enviados, como o total do universo levantado. consulta.

Os dados demonstram que as trinta escolas $(100,0 \%)$ possuem livros para

As informações obtidas sobre os tipos e o número de livros existentes encontram-se dispostos escola por escola em quadro (Anexo III).

Através desse quadro, constata-se que as 30 escolas $(100,0 \%)$ possuem livros específicos em Enfermagem; 29 tem dicionário de Português $(96,6 \%)$ e o de Termos Médicos encontramos em $26(86,6 \%)$. Nas Escolas o número total de livros existentes varia de algumas dezenas até milhares.

Este livros, segundo as respostas recebidas, estão localizados em biblioteca em 23 escolas $(76,6 \%)$. Nas 7 escolas restantes encontram-se em outro local físico, quatro em estantes $(13,3 \%)$, e, $3(10,0 \%)$ em sala privativa: diretoria, secretaria, etc.

Em resposta à pergunta sobre área física, 26 escolas declararam possuir acomodação para os consulentes $(86,6 \%)$.

Normas escritas de funcionamento, segundo este levantamento, existem em 20 escolas $(60,6 \%)$. 
O horário de funcionamento das bibliotecas é muito variado, conforme se pode observar no quadro a seguir.

QUADRO

Número de Escola e horário de funcionamento das mesmas.

\begin{tabular}{lrr}
\hline Horário de funcionamento & N.o de escolas & $\%$ \\
\hline Manhãa & 1 & 3,3 \\
Tarde & 2 & 6,6 \\
Noite & 1 & 3,3 \\
Manhã e tarde & 14 & 46,6 \\
Manhã, tarde e noite & 5 & 16,6 \\
Não tem horário fixo & 6 & 20,0 \\
Manhã e noite & 1 & 3,3 \\
\hline
\end{tabular}

Os consulentes têm acesso direto aos livros em 22 escolas $(73,3 \%)$ e é feito empréstimos de livros por mais de dois dias em 18 escolas $(60,0 \%)$.

Os livros estão catalogados em 24 escolas $(80,0 \%)$; em uma apenas alguns livros $(3,3 \%)$ e em 5 escolas nenhum livro está catalogado $(16,6 \%)$.

Existem fichários em 23 escolas $(76,6 \%)$.

Os docentes e discentes opinam na aquisição de livros em 25 escolas $(83,3 \%)$; em 4 apenas os docentes $(13,3 \%)$; e, em 1 nenhum opina $(3,3 \%)$.

Os tipos de periódicos existentes nas escolas e o seu modo de aquisição estão apresentados no Quadro 2 (Anexo IV). Pode-se notar que a maioria das escolas adquire os periódicos através de compra e doação. A pergunta é rara e utilizada somente para revistas.

As revistas são adquiridas: em 14 por doação e compra $(46,6 \%)$; em 7 por compra $(23,3 \%)$; em 3 por doaçãc $(10,0 \%)$; em 1 por compra, doação e permuta $(3,3 \%)$ e 5 escolas não responderam o modo de aquisição $(16,6 \%)$.

Comparando-se às revistas, os jornais são adquiridos, de modo geral, em menor número de escolas: 9 adquiriram por doação $(30,0 \%)$; 5 por compra $(16,6 \%) ; 3$ por compra e doação $(10,0 \%)$ e 10 não responderam o modo de aquisição $(33,3 \%)$.

Quanto a periódicos existentes em cada escola, encontramos 19 com jornal e revista $(63,3 \%) ; 6$ possuindo apenas revista $(20,0 \%)$, e, uma apenas jornal $(3,3 \%)$. Quatro escolas não responderam a essa questão.

Concluindo: em 25 escolas existem revistas $(83,3 \%)$ em 20 escolas jornal $(66,6 \%)$.

O resultado obtido permitiu constatar que todas as Escolas e Cursos de Auxiliar de Enfermagem do Estado de São Paulo possuem recursos para consulta bibliográfica dos consulentes.

Constatou-se também que, na maioria delas, há uma área física específica e uma organização de funcionamento, o que invalida as hipóteses número dois e três.

\section{CONCLUSÕES}

Pelos resultados obtidos verificou-se que todas as Escolas e Cursos de Auxilir de Enfermagem do Estado de São Paulo possuem livros para consulta; e em 25 delas existem revistas específicas em Enfermagem $(83,3 \%)$. 
$\mathrm{Na}$ grande maioria das escolas estes livros estão em Biblioteca com acomoação para os consulentes, tendo eles acesso direto aos livros.

As referidas bibliotecas possuem fichário, normas escritas de funcionamento e atendem predominantemente no periodo da manhã e tarde.

Muitos aspectos por esclarecer, como a existência ou não de bibliotecário e a média de frequiência de consultas às referidas bibliotecas, pois isso exigiria uma pesquisa mais detalhada.

As conclusões a que chegamos através dos resultados deste levantamento fazem-nos acreditar que a existência de bibliotecas e sua utilização pelos alunos e docentes influem no nível de ensino destas Escolas e Cursos de Auxiliar de Enfermagem do Estado de São Paulo.

YAMAMOTO, A. \& HIRATA, L. K. Libraries of Schools and Schools for Practical Nurses in São Paulo, Brasil. Rev. Esc. Enf. USP, São Paulo, 14(1):89-99, 1980.

This is a survey made in thirty nine Schools for Practical Nurses in São Paulo, Brasil, 1978, about library resources. The aspects surveyed were number and type of books and journals, physical area used as library and its organization.

\section{REFERENCIAS BIBLIOGRAFICAS}

1. BORDENAVE, J. D. \& PEREIRA, A. M. A biblioteca como instrumento de ensino-aprendizagem. In: Estratégias de ensino-aprendizagem. Petrópolis, Vozes, 1977. cap. 11, p. 255-65.

2. CALDAS, N. P. Organização da biblioteca para esccla ou cursos de auxiliares de enfermagem. Rev. Bras, Enf., Rio de Janeiro, 21(2): 85-101, abr./jun., 1968.

3. CaRvalho, A. C. Padrōes mínimos para escolas de enfermagem. Rev. Bras. Enf., Rio de Janeiro, 15(5): 386-99, out., 1968.

4. ENCICLOPEDIA BARSA. São Paulo, Encyclopaedia Britannica, 1960. p. 125.

5. GRANDE ENCICLOPEDIA DELTA LAROUSSE. Rio de Janeiro, Delta, 1970. p. 892.

6. GUINEE, $K$. Provision de serviços de biblioteca. In: - Enseñanza de enfermería: objetivos y métodos. México, Interamericana, 1967. cap. 1, p. 18-9.

7. HEIDGERKEN, L. Elaboración de planes diarios: empleo de la biblioteca. In: Enseñanza en la escuelas de enfermerfa. 3. ed. México, Interamericana, 1964. cap. 9, p. 284.

8. MARQUES, J. C. Métodos e técnicas de ensino. In: - Paradigma para análise do ensino. Porto Alegre, Globo, 1977. cap. 10, p. 142.

9. MEDEIROS, N. R. D. Relatório da Comissẫo de Documentação e Estudos da ABEn - $1975 / 1976$. Rev. Bras. Enf., Brasília, 29(4): 204-8, out./dez., 1976.

10. NERICI, I. G. Material didático: biblioteca geral e especializada. In: —__ Didática geral. 3. ed. Sảo Paulo, Fundo de Cultura, 1965. cap. 10, p. 315.

11. NOGUEIRA, $O$. Plano e relatório de pesquisa. In: - Pesquisa social: métodos e técnicas. 3. ed. São Paulo, Nacional, 1975. Parte 2, p. 160-8.

12. ORGANIZACION PANAMERICANA DE LA SALUD. Organización de una escuela de enfermería. In: Guia para escuelas de enfermeria en la America Latina. Washington, OPS/OMS, 1961. cap. 5, p. 49-50. (Publicación cientifica, 55).

13. PRADO, H. A. Como se organiza uma biblloteca. 2. ed. São Paulo, Lep. ,1953. 120 p.

14. SCHRAMN, A. Biblioteca da escola de enfermagem. Rev. Bras. Enf., Rio de Janeiro, 18(2/3): 127.35, abr./Jun., 1965.

15. SEILTIZ, $C$. et alil. $O$ relatório de pesquisa. In: socials. 2. ed. São Paulo, Herder, 1967. cap. 12, p. 497-508.

16. WITT, A. Metodologla de pesquisa. 2. ed. Sẽo Paulo, Resenha Tributária, 1973.141 p. 


\section{ANEXO I}

\section{CARTA DE APRESENTAÇÃO}

São Paulo, 08 de maio de 1978

Exmo. Sr. Diretor.

As alunas da Escola de Enfermagem solicitam a valiosa colaboração de V.S. para um levantamento a ser realizado sobre as bibliotecas das Escolas ou Cursos de Auxiliar de Enfermagem do Estado de São Paulo. Este trabalho constitui uma atividade do programa de Prática de Ensino do Curso de Licenciatura da Universidade de São Paulo. Necessitamos pois, de alguns dados gerais sobre a biblioteca da Escola ou Curso dirigido por V.S.

Anexamos um questionário e solicitamos o obséquio de preenchê-lo e devolvê-lo no máximo até o dia 29 de maio. Para isso enviamos junto um envelope selado para resposta.

Sem mais, contando com a sua colaboração, agradecemos antecipadamente.

Subscrevemos

$\overline{\text { Atsuko Yamamoto }} \overline{\text { Lourdes Kimie Hirata }}$

Victória Secaf

Docente de Prática de Ensino 


\section{ANEXO II \\ QUESTIONARIO}

1. A Escola ou Curso tem livros para uso dos alunos e docentes?

$$
\text { Sim ( ) Não ( ) }
$$

Em caso afirmativo, esses livros ficam numa:

- biblioteca ( )

- estante ou armário ( )

- sala privativa (diretoria, secretaria, etc.) ( )

2. Há acomodação (mesas e cadeiras) para os consulentes?

$$
\operatorname{Sim}(\text { ) Não () }
$$

3. Existem normas escritas de funcionamento? $\operatorname{Sim}($ )

Não ( )

4. Qual o horário de funcionamento?

$$
\begin{aligned}
& \text { Manhã, das } 8 \text { às } 12 \text { horas ( ) } \\
& \text { Tarde, das } 12 \text { às } 18 \text { horas ( ) } \\
& \text { Noite, das } 18 \text { às } 22 \text { horas ( ) } \\
& \text { Não tem horário fixo }
\end{aligned}
$$

5. O consulente tem acesso direto ao livro? Sim ( )

Não ( )

6. Existem empréstimos? Sim ( ) Não ( )

Em caso afirmativo, qual a duração?

$$
1 \text { dia ( ) } 2 \text { dias ( ) }
$$

mais de 2 dias ( )

7. Existe fichário? Sim ( ) Não ( )

8. Os livros estão catalogados? Sim ( ) Não ( )

9. O corpo docente e discente opinam na aquisição de novos livros ou de mais exemplares dos já existentes?

$$
\text { Sim ( ) Näo ( ) }
$$

10. Quais os tipos de livros que existem?

- específicos na área de enfermagem ( )

— não específicos na área do enfermagem ( )

- literatura ( )

- dicionário de português ( )

- dicionário de termos médicos ( )

11. Qual a média de livros existentes?

12. Tem periódicos? revistas específicas em enfermagem ( ) jornais ( )

Em caso afirmativo, eles são adquiridos através de

$\begin{array}{llll}\text { - revistas: } & \text { doação ( ) } & \text { compra ( ) } & \text { permuta ( ) } \\ \text { - jornais : } & \text { doação ( ) } & \text { compra ( ) } & \text { permuta ( ) }\end{array}$


Escolas, tipo de livros e número total de livros existentes

\begin{tabular}{|c|c|c|c|c|c|c|}
\hline $\begin{array}{l}\text { 号 } \\
\text { 品 }\end{array}$ & 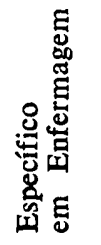 & 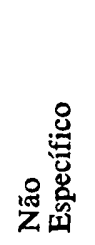 & 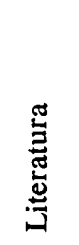 & 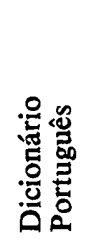 & 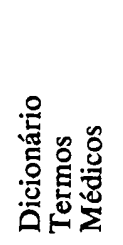 & 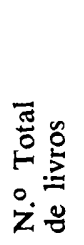 \\
\hline 01 & $X$ & $\mathbf{X}$ & - & $\mathbf{X}$ & $X$ & 3000 \\
\hline 02 & $X$ & $X$ & $X$ & $X$ & $X$ & 5089 \\
\hline 03 & $X$ & $X$ & $X$ & $X$ & $X$ & 1100 \\
\hline 04 & $x$ & $X$ & - & $X$ & $X$ & 2279 \\
\hline 05 & $X$ & $x$ & $X$ & $\mathbf{X}$ & $x$ & 177 \\
\hline 06 & $\mathbf{X}$ & - & - & - & $X$ & - \\
\hline 07 & $X$ & $x$ & - & $X$ & $X$ & 250 \\
\hline 08 & $X$ & $x$ & $X$ & $\mathbf{X}$ & $x$ & 1181 \\
\hline 09 & $x$ & $x$ & - & $\mathbf{x}$ & $X$ & 1200 \\
\hline 10 & $X$ & - & - & $x$ & $\mathrm{X}$ & 100 \\
\hline 11 & $X$ & $X$ & $X$ & $\mathbf{X}$ & $X$ & 5000 \\
\hline 12 & $\mathbf{X}$ & $X$ & $x$ & $x$ & $\mathbf{X}$ & 2000 \\
\hline 13 & $X$ & $x$ & $X$ & $\mathbf{X}$ & $X$ & 300 \\
\hline 14 & $X$ & $X$ & $X$ & $\mathbf{X}$ & 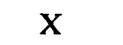 & - \\
\hline 15 & $X$ & $\mathrm{X}$ & $X$ & $X$ & $X$ & - \\
\hline 16 & $X$ & - & - & $\mathbf{X}$ & - & 33 \\
\hline 17 & $X$ & $X$ & - & $\mathbf{X}$ & $\mathbf{X}$ & 120 \\
\hline 18 & $\mathbf{X}$ & $x$ & $\mathbf{X}$ & $\mathbf{X}$ & $X$ & 1500 \\
\hline 19 & $X$ & $X$ & $X$ & $\mathbf{x}$ & $\mathbf{X}$ & 600 \\
\hline 20 & $\mathbf{X}$ & $\mathbf{X}$ & $\mathbf{X}$ & $\mathrm{X}$ & $X$ & 3000 \\
\hline 21 & $X$ & $x$ & $\mathbf{X}$ & $x$ & - & 1321 \\
\hline 22 & $X$ & $X$ & - & $x$ & $X$ & 170 \\
\hline 23 & $x$ & $\mathbf{X}$ & $\mathbf{X}$ & $X$ & $x$ & 600 \\
\hline 24 & $\mathbf{X}$ & $\mathbf{X}$ & $\mathbf{X}$ & $x$ & $\mathbf{X}$ & 4000 \\
\hline 25 & $\mathbf{X}$ & $\mathbf{X}$ & - & $x$ & $X$ & 150 \\
\hline 26 & $\mathrm{x}$ & $\mathbf{x}$ & - & $x$ & - & - \\
\hline 27 & $x$ & $X$ & - & $x$ & $X$ & 200 \\
\hline 28 & $X$ & $x$ & - & $\mathbf{X}$ & - & 500 \\
\hline 29 & $X$ & $x$ & $\mathbf{X}$ & $x$ & $x$ & 7614 \\
\hline 30 & $X$ & - & $X$ & $\mathrm{X}$ & $\mathrm{X}$ & 70 \\
\hline $\begin{array}{c}\text { Total } \\
\%\end{array}$ & $\begin{array}{c}30 \\
100,0\end{array}$ & $\begin{array}{l}26 \\
86,6\end{array}$ & $\begin{array}{l}17 \\
56,6\end{array}$ & $\begin{array}{l}29 \\
96,6\end{array}$ & $\begin{array}{l}26 \\
86,6\end{array}$ & \\
\hline
\end{tabular}




\section{ANEXO IV \\ QUADRO 2}

Relação das Escolas, periódicos existentes e modo de aquisição.

\begin{tabular}{|c|c|c|c|c|c|c|}
\hline \multirow[b]{2}{*}{$\begin{array}{l}\text { 芯 } \\
\text { 岗 }\end{array}$} & \multicolumn{3}{|c|}{$\begin{array}{l}\text { Revistas específicas } \\
\text { de enfermagem }\end{array}$} & \multicolumn{3}{|c|}{ Jornais } \\
\hline & 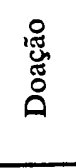 & $\begin{array}{l}\frac{\pi}{0} \\
\text { 号 }\end{array}$ & 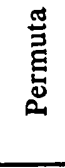 & 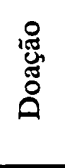 & 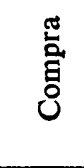 & 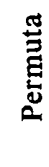 \\
\hline 01 & $\mathbf{X}$ & $\mathbf{X}$ & - & $?$ & $?$ & $?$ \\
\hline 02 & $\mathrm{X}$ & $\mathbf{X}$ & $\mathrm{X}$ & - & $X$ & - \\
\hline 03 & - & $\mathbf{X}$ & - & $\mathrm{X}$ & - & - \\
\hline 04 & - & $X$ & - & $x$ & - & - \\
\hline 05 & $\mathbf{X}$ & $x$ & - & $X$ & - & - \\
\hline 06 & $X$ & $\mathbf{X}$ & - & $\mathrm{X}$ & - & - \\
\hline 07 & $\mathbf{X}$ & $x$ & - & - & $x$ & 一 \\
\hline 08 & $\mathbf{X}$ & $X$ & - & $X$ & - & - \\
\hline 09 & $\mathbf{X}$ & $\mathbf{X}$ & - & - & - & 一 \\
\hline 10 & $\mathrm{X}$ & $X$ & - & - & - & 一 \\
\hline 11 & - & - & - & - & - & 一 \\
\hline 12 & - & $\mathbf{X}$ & - & - & $\mathrm{x}$ & - \\
\hline 13 & $\mathrm{X}$ & $\mathbf{X}$ & - & $?$ & $?$ & $?$ \\
\hline 14 & $X$ & $\mathbf{X}$ & - & $X$ & $\mathrm{X}$ & - \\
\hline 15 & $X$ & $x$ & - & 一 & - & - \\
\hline 16 & - & $x$ & - & - & $x$ & 一 \\
\hline 17 & $\mathbf{X}$ & - & - & $?$ & $?$ & $?$ \\
\hline 18 & $\mathrm{X}$ & - & - & $\mathbf{X}$ & - & - \\
\hline 19 & - & - & - & $\mathbf{X}$ & - & 一 \\
\hline 20 & $\mathbf{X}$ & $X$ & - & $\mathrm{X}$ & $X$ & 一 \\
\hline 21 & $\mathbf{x}$ & $\mathbf{X}$ & - & $\mathbf{X}$ & $x$ & - \\
\hline 22 & - & $\mathbf{X}$ & - & - & - & 一 \\
\hline 23 & $x$ & $\mathbf{X}$ & - & - & - & 一 \\
\hline 24 & $\mathrm{X}$ & $X$ & - & - & - & 一 \\
\hline 25 & - & $x$ & - & - & $X$ & 一 \\
\hline 26 & - & - & - & - & - & - \\
\hline 27 & - & $\mathrm{X}$ & - & $\mathbf{x}$ & - & 一 \\
\hline 28 & - & - & - & - & - & - \\
\hline 29 & - & - & - & $\bar{x}$ & - & - \\
\hline 30 & $\mathrm{X}$ & - & - & $\mathbf{X}$ & - & - \\
\hline $\begin{array}{c}\text { Total } \\
\%\end{array}$ & $\begin{array}{l}18 \\
60,0\end{array}$ & $\begin{array}{l}22 \\
73,3\end{array}$ & $\begin{array}{r}01 \\
3,3\end{array}$ & $\begin{array}{c}12 \\
40,0\end{array}$ & $\begin{array}{c}08 \\
26,6\end{array}$ & - \\
\hline
\end{tabular}

(?)) = Sim, mas sem especificar o modo de aquisição. 